\title{
Differences between the Geotechnical Campaigns at Front-End Engineering Design (FEED) and Detailed Design-A Case Study
}

\author{
Emmanouil Spyropoulos ${ }^{1}$, Adil Khan ${ }^{2}$ \\ ${ }^{1}$ Saudi Aramco, Dhahran, Kingdom of Saudi Arabia \\ ${ }^{2}$ Soil Improvement Contracting Co., Dammam, Kingdom of Saudi Arabia \\ Email: emmanouil.spyropoulos@aramco.com, adil@sic-sa.net
}

How to cite this paper: Spyropoulos, E. and Khan, A. (2020) Differences between the Geotechnical Campaigns at Front-End Engineering Design (FEED) and Detailed Design-A Case Study. World Journal of Engineering and Technology, 8, 590-604. https://doi.org/10.4236/wjet.2020.84041

Received: August 27, 2020

Accepted: September 13, 2020

Published: September 16, 2020

Copyright (c) 2020 by author(s) and Scientific Research Publishing Inc. This work is licensed under the Creative Commons Attribution International License (CC BY 4.0).

http://creativecommons.org/licenses/by/4.0/

\begin{abstract}
This paper presents a case study of the geotechnical conditions encountered within a project at Saudi Arabia at both the Front-End Engineering Design (FEED) and Detailed Design geotechnical campaigns. The soil formations were considerably varied between the two investigations resulted in extensive ground improvement activities that have not been anticipated within the FEED stage. The overall objectives of such study are to explore the soil formations found, and to evaluate/summarize the soil treatment measures necessary for each of the two different campaigns in order for the project specifications in relation to settlement, bearing capacity, and liquefaction potential to be achieved. Moreover, the potential factors that may have affected the differences on the strength/density of the soils within the two different geotechnical campaigns that have been carried out at nearby locations are also explored. Based on the analysis conducted, it is concluded that soil strength on the FEED data is much higher compared to the strength on the Detailed Design soil data resulted on shifting the soil mitigation measures from light to severe, hence, leading to project both excessive cost and considerable increase on time schedule.
\end{abstract}

\section{Keywords}

SPT, Density, FEED, Detailed, Geotechnical

\section{Introduction}

International institutions defined FEED as "Front End Engineering Design". The basic engineering that follows the Conceptual Design is termed as the FEED. At the FEED design stage, the technical requirements and the economic feasibility 
aspects are focused on. The FEED can be separated into different packages, each covering a specific portion of the project. The packages are then used as basis for the Execution Phase Contracts bidding which includes, Engineering and Procurement Construction (EPC), Engineering Procurement Construction and Installation (EPCI), Early Contractor Involvement (ECI), Lump Sum Turn Key (LSTK), etc. and is used as design basis.

Identification of a good FEED is the reflection of all project-specific client requirements and the lack of significant changes during execution phase. It is typical for FEED contracts to take as long as a year to complete for large-sized projects. A close communication is key between Project Owners, Operators and the Engineering Contractor to create or assess project specific requirements.

As mentioned by [1], at the preliminary stage despite having less information, engineers have to make sound investment decisions, even though the available resources to tackle the made decisions continue to shrink. By opting for a multi-disciplinary and concurrent workflow, process industries can ensure all engineering decisions made at the initial conceptual design and front-end engineering phases of a project are based in sound asset life-cycle knowledge and the best design practices. Design decisions, involving plant layout and material selection which are typically decided at a detailed design stage, can now be made at the FEED stage with proper implementation.

Additionally, [1] concluded that opting to incorporate conceptual design and FEED stages, higher efficiency or productivity and a faster project duration is achieved. The FEED stage offers an opportunity for implementing the best design practices.

As per [2], assessing the maturity of FEED (particularly for large scaled projects) is an important task that has a lasting influence during the project operation and ultimately the project success. It should give the project owner tools, whereby the party can make sound decisions regarding projected costs and schedule predictions, indication of when a specific phase should be completed and the next be entered into, decrease the level of unforeseen uncertainties by significant amount and the impact of FEED maturity that can be observed in all phases. Additionally, numerous authors focused on FEED maturity and the subsequent impact on project performance from an economical point of view, i.e. reduced costs and less change in schedules. Projects with high FEED maturity substantially outperformed projects with lower maturity by $20 \%$ in terms of cost growth related to the approved budget [3].

[3] summarized the advantages and disadvantages of both ECI (Early Contractor Involvement) and FEED phase as follows:

Advantages of FEED \& ECI phase:

- Identification and mitigation (or proper allocation and remediation pricing) of risks at preliminary stage, removing contingency to a substantial degree, so parties may adopt more realistic risk-adjusted prices.

- Costs related to tendering are reduced as only a single design process is undertaken. 
- With early contractor involvement in the design and pricing, value for money is achieved.

- Increased transparency/clarity that allows better decision-making as a result of discussions and deeper understanding of project requirement.

- Efficiency of production due to optimized (for project-specific requirements) construction and increased profitability by the reduction of operating costs.

- Unique solutions can be created for a project as the parties work together as partners, thereby reducing the risks of misunderstandings as a result of a transparent relationship.

Disadvantages of FEED \& ECI phase (from an Owner's perspective):

- Where risk in the construction phase remains high, risk sharing aspect is reduced.

- There is a strong requirement of commitment from the top management of both the project owner as well as the contractor for the overall project as transparency, an integrated team and open communication are the basis of the ECI method.

Competitive analysis, definition of the scope and operations/execution planning that takes place during the FEED stage drives decisions related to the execution of major projects. The FEED is the most important stage where the design is easily influence and at a relatively low cost and effect to time schedule. Unfortunately, the FEED stage is typically neglected by reducing the allotted time and resources for the stage in an attempt to reach a shorter project schedule [4].

Therefore, based on international and long experience in dealing with number of small and big projects, authors of this paper are intended to conduct this comprehensive study based on a real data to explore the differences, discrepancies on quality, costing and timing by applying the FEED and Detailed Design approaches. The main objective of this paper is to reinforce the findings of the above-mentioned research and studies by emphasizing the importance of the FEED design, especially, on matters related to the soil formations. Poor assessment of the FEED geotechnical findings can lead to considerable variations compared to the post-award soil information (in terms of strength and density) which may lead either to excessive soil mitigations increasing the cost and time-schedule of a project or over-conservatism that has increased the initial bidding price.

\section{Methodology}

\subsection{Study Area}

The test site is a selected infrastructure project in the southern part of Saudi Arabia. Both the FEED and the Detailed Design concepts on the geotechnical matters were assessed and the reasons of identifying different soil formations at more or less similar locations of testing were also examined. This was made possible with reference to the soil improvement techniques utilized and the de- 
tailed assessment of geotechnical condition (parameters) encountered at the test site at both phases.

A large area within this project was constructed on soils that had been subject to improvement using various soil treatment schemes either deep or shallow type of mitigations as shown below in Table 1 .

Table 1. Various soil improvement schemes used within numerous facilities.

\begin{tabular}{cc}
\hline Areas/Facilities & Soil Treatment Method \\
\hline 1 & Vibro Stone Columns \\
2 & Dynamic Compaction \\
3 & Vibro Stone Columns \\
4 & Vibro Stone Columns \\
5 & Vibro Compaction \\
6 & Vibro Compaction \\
\hline
\end{tabular}

In general, soil treatment incorporates several techniques that can be appropriate to an extensive range of soil formations, load/footings configurations, and area settings/sizes. The selection procedures of the suitable ground improvement schemes are usually determined based, primarily, on the soil formations and the depth of treatment as well as on cost and time schedule considerations. However, it should be noted that not all soil treatment schemes are suitable and applicable to all soil settings. Irrespective of cost/time schedule considerations if a non-suitable ground improvement method is utilized, the enhancement (reinforcement) of the weak soils will not be satisfactory in relation to the defined acceptance criteria, and therefore alternative solutions will then have to be considered.

\subsection{Selection of Improvement Schemes}

The areas/facilities mentioned in Table 1 were subjected to challenging ground conditions and specifications (e.g. liquefaction, settlement tolerances), and therefore an ample design and planning as well as suitable quality control testing were required for completing those soil treatment works within the allowable time frames.

Selection of the suitable soil treatment schemes was based on the following elements:

- Nature of soils to be treated e.g. vibro stone columns for soft cohesive formations, and, vibro compaction/dynamic compaction for natural or reclaimed granular materials.

- Depth of improvement to be achieved (due to extensive depths where improvement was required, vibro-concept techniques were chosen in lieu of the traditional dynamic approaches).

- Based on calibration trial areas it was evident that vibro methodology techniques were adequate for mitigating all risks since all acceptance criteria have been addressed. 


\subsection{Exploratory Tests Locations}

\subsubsection{FEED Phase}

The FEED geotechnical investigation conducted covers eight (8) boreholes and other test data as per the work scope at the Test Site in southern Saudi Arabia. Out of the eight (8) boreholes, four boreholes were drilled to $50 \mathrm{~m}$ depth, and four boreholes were drilled to depths ranged from $15 \mathrm{~m}$ to $20 \mathrm{~m}$ (Table 2). Five of the FEED geotechnical boreholes were executed at the approximate locations of the facilities whereas the remaining three boreholes were undertaken at locations far away from the structures (Table 2).

Table 2. FEED boreholes depth and approximate location in reference to the various areas/facilities.

\begin{tabular}{cccc}
\hline Area/Facility & FEED Boreholes & Depth $(\mathrm{m})$ & Location \\
\hline 1 & A & 20 & Far \\
2 & B & 50 & Approximate \\
3 & C & 50 & Approximate \\
4 & D & 50 & Approximate \\
5 & E \& F & $20 \& 15$ & approximate/far \\
6 & G \& H & $50 \& 20$ & approximate/far \\
Total Boreholes: & & $\mathbf{8}$ No & \\
\hline
\end{tabular}

\subsubsection{Detailed Design Phase}

Detailed soil investigation was carried out at the footprint of the proposed facilities locations. Subsoil conditions were explored by drilling and sampling eighty boreholes. Twenty boreholes were drilled up to $100 \mathrm{~m}$ depth below the existing grade, fifty boreholes were drilled up to $50 \mathrm{~m}$ depth and the remaining boreholes were drilled up to $20 \mathrm{~m}$ depth.

\subsection{Soil Characteristics}

\subsubsection{FEED Phase}

FEED geotechnical report soil categorization based on the soil types encountered in the upper layers of the exploratory holes. As shown in Table 3, Group 1 pertains to formations comprising of granular soils in the upper layers followed by fine grained soils/granular soils while Group 2 corresponds to formations with fine grained soils in the upper layers followed by granular soils/fine grained soils.

Table 3. Soil types encountered at Groups 1 and 2.

\begin{tabular}{ccl}
\hline & No of Boreholes Covered & \multicolumn{1}{c}{ Soil Type } \\
\hline Group 1 & 4 & $\begin{array}{l}\text { Granular soils in the upper layers followed by } \\
\text { fine grained soils/granular soils }\end{array}$ \\
Group 2 & 4 & $\begin{array}{l}\text { Fine grained soil in the upper layers followed by } \\
\text { granular soils/fine grained soils }\end{array}$ \\
\hline
\end{tabular}




\subsubsection{Detailed Design Phase}

Detailed geotechnical report shows that pockets and layers of loose soils were encountered in the boreholes at various depths generally between 0 and $20 \mathrm{~m}$. Such formations were followed by generally sand deposits in medium dense condition.

\subsection{Soil Strength}

\subsubsection{FEED Phase}

A background to the in-situ Standard Penetration Test (SPT) taken at frequent intervals along the borehole depth is provided below:

SPT " $N$ " value is the number of hammer drops to advance the sampler by 300 $\mathrm{mm}$. SPT number " $\mathrm{N}$ " in soil depends of both the soil properties and SPT Hammer Efficiency. For the same soil, an SPT hammer with higher efficiency would provide a higher " $N$ " number than a SPT hammer with lower hammer efficiency. [5] states in section 9.3, "Variations in $\mathrm{N}$-values of $100 \%$ or more have been observed when using different standard penetration test apparatus and drillers for adjacent borings in the same soil formation."

Therefore, uncorrected "N" number should not be utilized for comparing soil conditions. The correct procedure is for the SPT " $\mathrm{N}$ " number to be corrected to $\mathrm{N}_{60}$ that is based on normalized SPT number for a $60 \%$ energy hammer. This eliminates the hammer dependency. A comparison based on "uncorrected" $\mathrm{N}$ numbers alone cannot be used as justification for soil change.

Within the FEED geotechnical report it is indicated that loose granular soils were observed at surface and within the top one meter in the majority of the boreholes. Few boreholes also show loose granular soils at discontinuous depths. Very loose granular soils were also noticed in few boreholes at varying depths. No weak soils in the form of very soft to soft cohesive materials were encountered to any of the areas.

The strength of the soils corresponding to the FEED boreholes by means of SPT $\mathrm{N}$ values at each respective area are provided in Figure 1 (SPT N values shown as 50 refers to SPT values of refusal which is greater than 50 ).

\subsubsection{Detailed Design Phase}

The strength of the soils corresponding to the detailed design boreholes at the center of the facilities by means of SPT N values is provided in Figure 2.

\section{Results}

Geotechnical results and findings directed for the comparative study are summarized in the following sections:

\subsection{Soil Settlements}

\subsubsection{FEED Phase}

Structure settlement analysis within the FEED have considered typical loading conditions assumed to be $100 \mathrm{kPa}$ for the Group 2 soils and $200 \mathrm{kPa}$ for the 
SPT N Value - FEED Boreholes

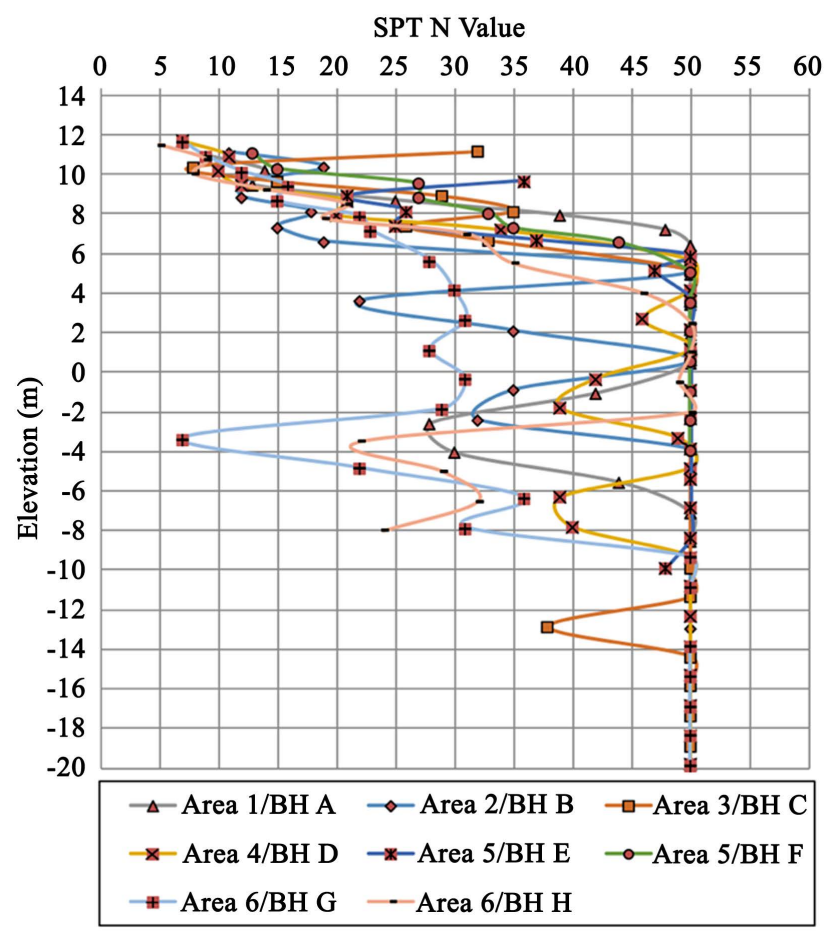

Figure 1. Strength of the soils corresponding to the FEED boreholes by means of SPT N values at each respective area.

SPT N Value - Detailed Investigation Boreholes (Center of Structures)

SPT N Value

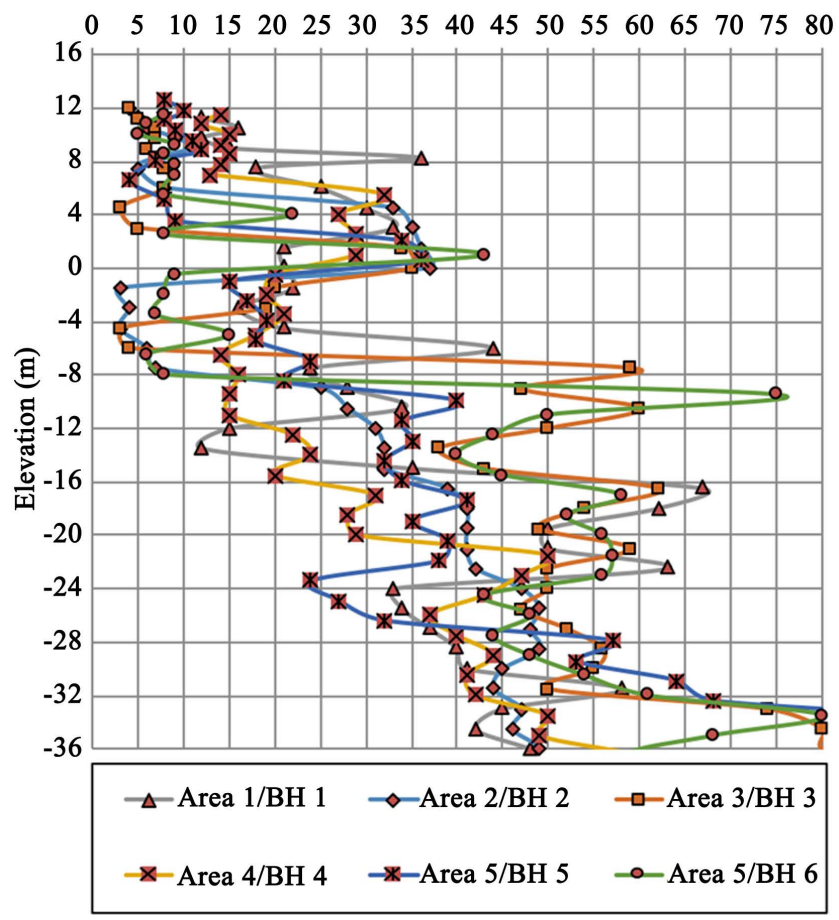

Figure 2. Strength of the soils corresponding to the detailed design boreholes by means of SPT N values at the center of the proposed structures at each respective area. 
Group 1 soils. The settlement analysis has been carried out for both the elastic (within the granular) and consolidation (within the cohesive) elements. Settlement analysis based on [6] method considering a creep factor for long-term (secondary) elastic settlements in sands (with an elapsed time of 5 years).

Structure settlements were reasonable estimated by assuming that the stress influence zones extend to depths of approximately $50 \mathrm{~m}$ (covering the case of utilizing mat foundations). The estimated settlements at all different areas based on the borehole locations are shown in Table 4.

Table 4. FEED estimated settlements at all different areas.

\begin{tabular}{cccccc}
\hline \multirow{2}{*}{ Soil Type } & Pressure & Boreholes & \multicolumn{3}{c}{ Settlements } \\
\cline { 4 - 6 } & $(\mathrm{kPa})$ & Covered & Elastic $(\mathrm{mm})$ & Consolidation $(\mathrm{mm})$ & Total $(\mathrm{mm})$ \\
\hline Group 1 & 200 & C, F, G, H & 115 & 60 & 175 \\
Group 2 & 100 & A, B, D, E & 58 & 127 & 185 \\
\hline
\end{tabular}

In Group 1 soils, subjected to applied pressure of $200 \mathrm{kPa}$ (highest load), the estimated settlements are $175 \mathrm{~mm}$. Likewise, in Group 2 soils, subjected to applied pressure of $100 \mathrm{kPa}$ (highest load), the estimated settlements are $185 \mathrm{~mm}$. In addition to the above given settlements, additional settlements of about $10 \%$ may be expected due to secondary compression effects. Additional settlements also do take place due to the proximity of other adjacent structures. The magnitude of these additional settlements is a function of relative distance between the facilities.

Therefore, the estimated settlements having considered $10 \%$ increase (due to secondary effects) are illustrated in Table 5.

Table 5. FEED estimated settlements considering $10 \%$ increase due to secondary compression effects.

\begin{tabular}{cccc}
\hline Soil Type & Pressure $(\mathrm{kPa})$ & Boreholes Covered & Total Settlements $(\mathrm{mm})$ \\
\hline Group 1 & 200 & C, F, G, H & 193 \\
Group 2 & 100 & A, B, D, E & 204 \\
\hline
\end{tabular}

\subsubsection{Detailed Design Phase}

Structure settlement analysis within the detailed geotechnical report has considered actual imposed maximum loads of $220 \mathrm{kPa}$. The estimated settlements at center of the structures are provided in Table 6.

Table 6. Detailed design estimated settlements at areas/structures center.

\begin{tabular}{ccccc}
\hline Area & $\begin{array}{c}\text { Pressure } \\
(\mathrm{kPa})\end{array}$ & $\begin{array}{c}\text { Elastic Settlement } \\
(\mathrm{mm})\end{array}$ & $\begin{array}{c}\text { Consolidation } \\
\text { Settlement }(\mathbf{m m})\end{array}$ & $\begin{array}{c}\text { Total Settlement } \\
(\mathbf{m m})\end{array}$ \\
\hline 1 & 220 & 376 & 0 & 376 \\
2 & 220 & 110 & 1059 & 1169 \\
3 & 220 & 496 & 263 & 759 \\
4 & 220 & 230 & 311 & 541 \\
5 & 220 & 407 & 172 & 579 \\
6 & 220 & 79 & 767 & 846 \\
\hline
\end{tabular}




\subsection{Site Class Liquefaction}

The site classification procedure for assigning site class, based on the types of soils present at the site and their engineering properties are prescribed in [7]. Based on the sub-soil stratigraphy revealed from the FEED and Detailed design geotechnical investigation, the site classification assessment has been done using SPT-N values/undrained shear strength values correlated to SPT-N values and cross-hole seismic tests.

\subsubsection{FEED Phase}

The analysis carried out reveals that the Site Class can be in general categorized into "Class D", or "Stiff Soil profile". Factor of safety against liquefaction hazard (based on the Site Class D) has been noted to be more than 1.5/2. Accordingly, the susceptibility to liquefaction is not be perceived in all areas.

\subsubsection{Detailed Design Phase}

The analysis carried out reveals that the Site Class in general can be categorized into "Class E". Potential of liquefaction was calculated by using appropriate software. Analysis carried out revealed that no liquefaction potential exists.

\section{Comparison between Feed and Detailed Investigations}

\subsection{Soil Strength}

A comparison of the soil strength corresponding to the FEED and Detailed Geotechnical Reports by means of SPT N values are illustrated in Figures 3-8.

Area 1

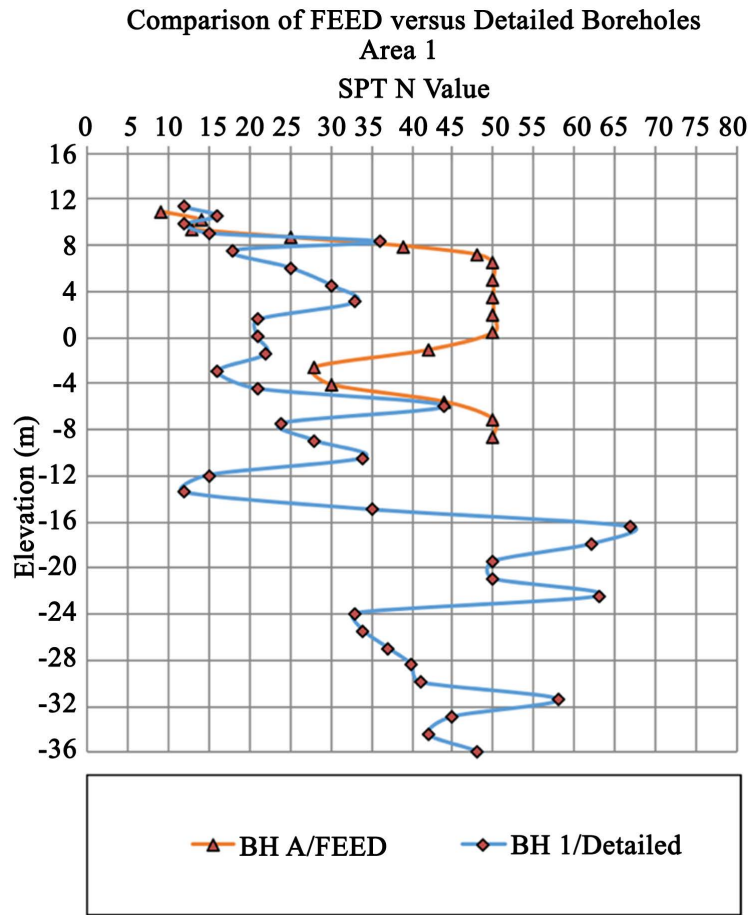

Figure 3. Strength comparison between the FEED and detailed campaigns for Area 1. 
Area 2

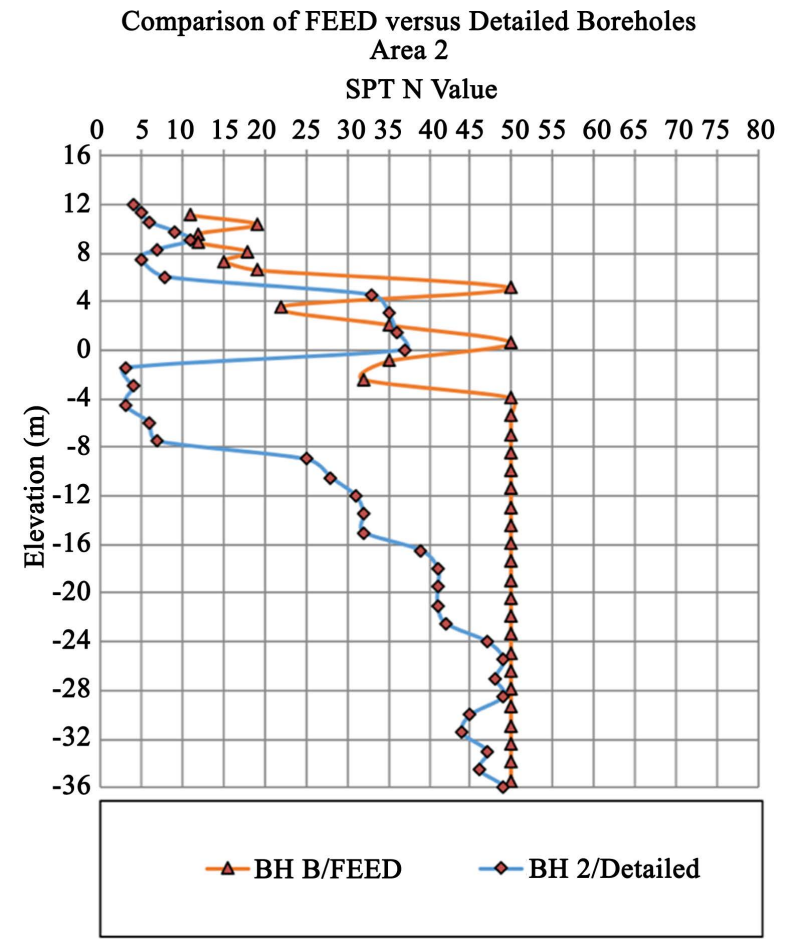

Figure 4. Strength comparison between the FEED and detailed campaigns for Area 2.

Area 3

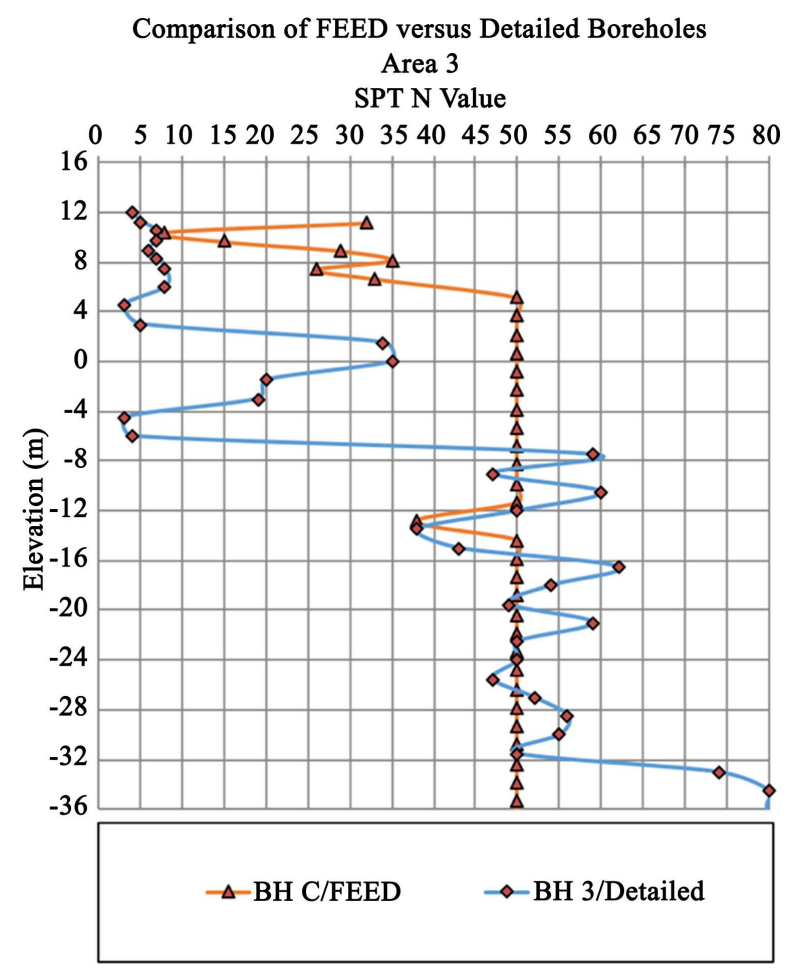

Figure 5. Strength comparison between the FEED and detailed campaigns for Area 3. 
$\underline{\text { Area } 4}$

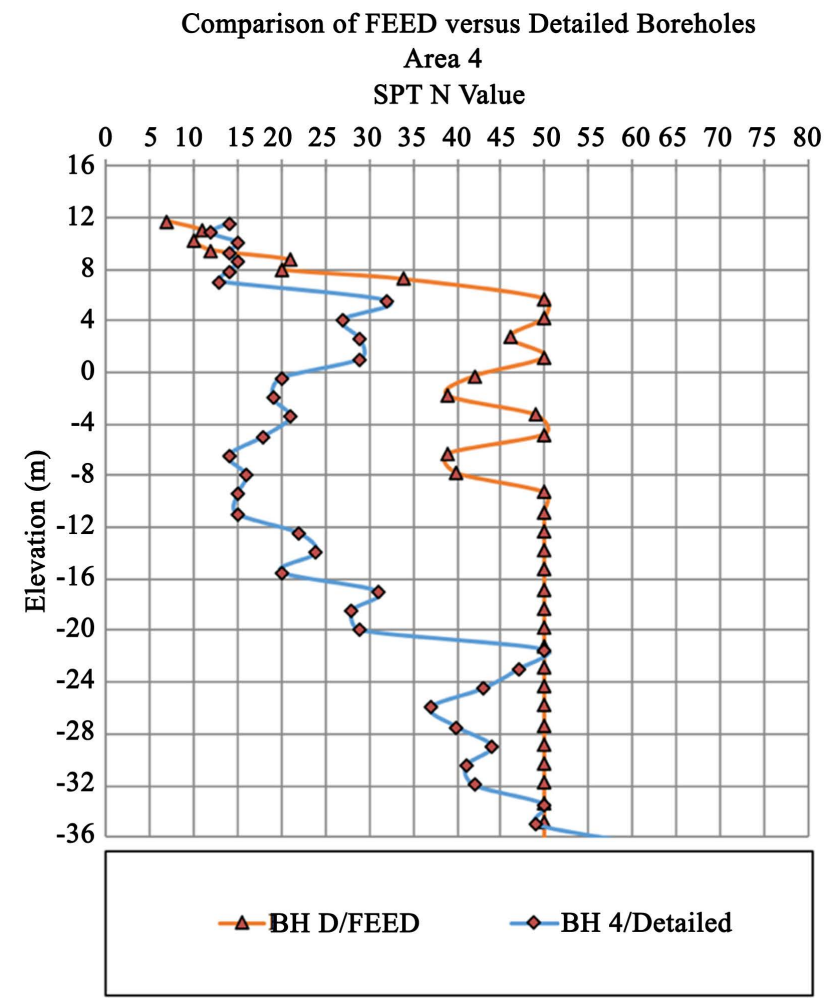

Figure 6. Strength comparison between the FEED and detailed campaigns for Area 4.

Area 5

\section{Comparison of FEED versus Detailed Boreholes \\ Area 5}

SPT N Value

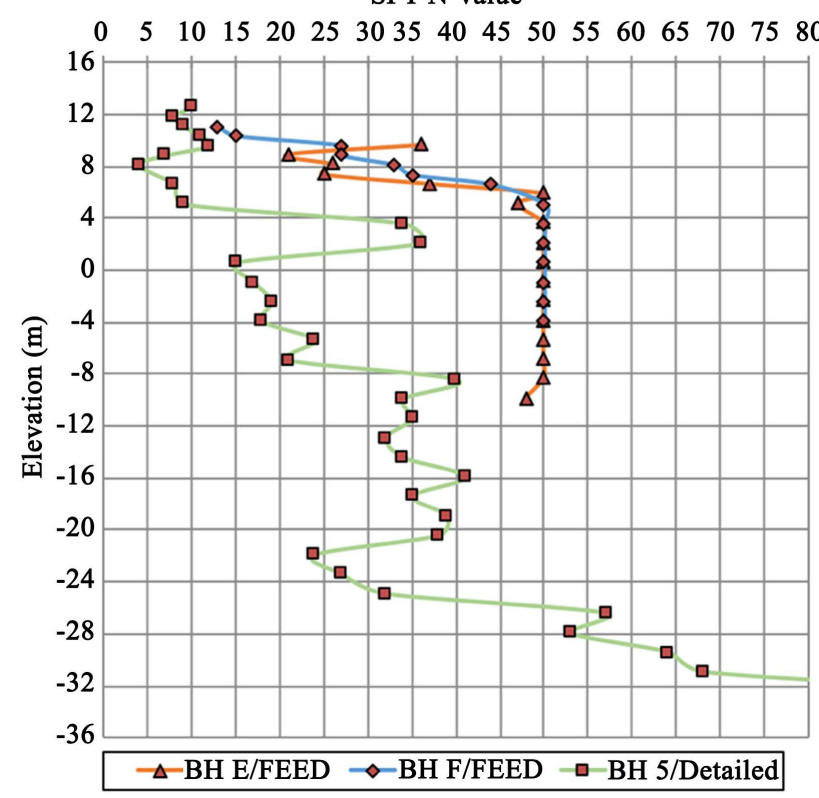

Figure 7. Strength comparison between the FEED and detailed campaigns for Area 5. 
$\underline{\text { Area } 6}$

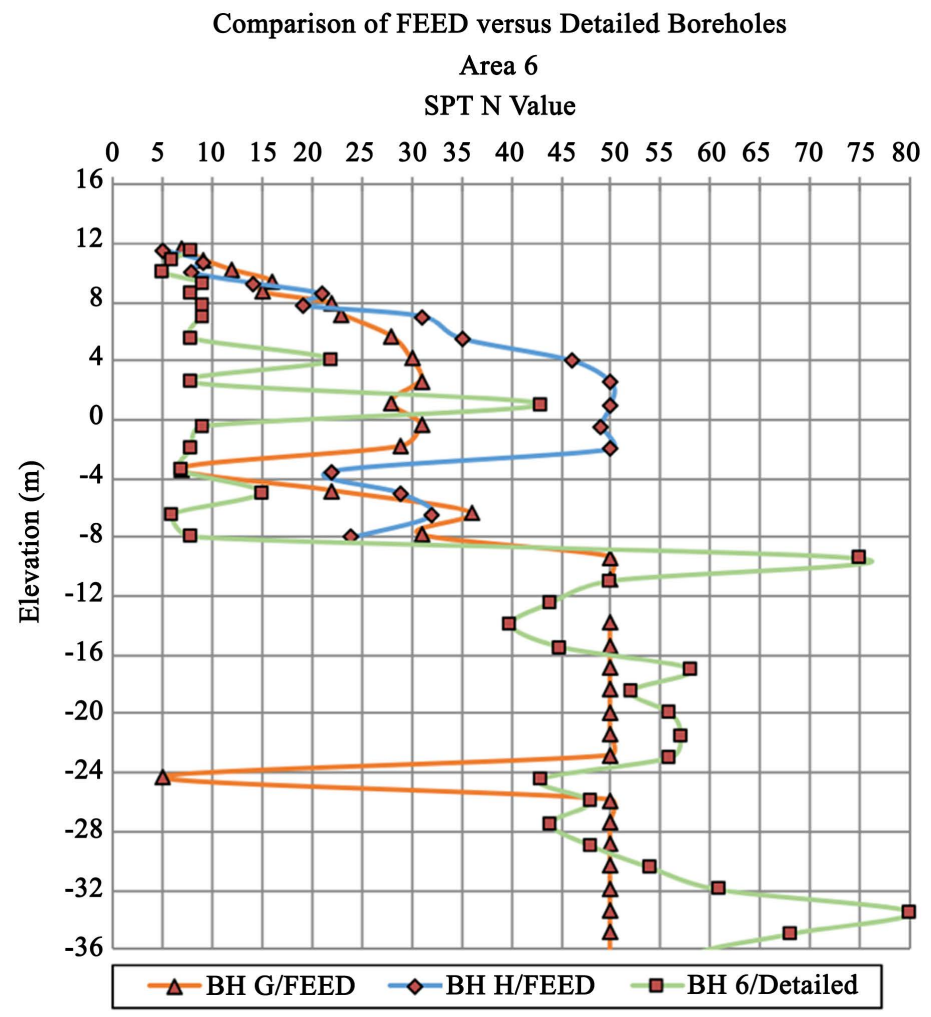

Figure 8. Strength comparison between the FEED and detailed campaigns for Area 6.

\subsection{Settlements Comparison}

A comparison of the settlements within the structures as retrieved from the FEED and detailed geotechnical reports are shown in Table 7.

Table 7. Comparison between FEED and detailed design estimated settlements at areas.

\begin{tabular}{cccc}
\hline Area & $\begin{array}{c}\text { Detailed Total Settlement } \\
(\mathrm{mm})\end{array}$ & $\begin{array}{c}\text { FEED Total Settlement } \\
(\mathrm{mm})\end{array}$ & $\begin{array}{c}\text { Detailed > FEED by } \\
\text { Percentage Difference (\%) }\end{array}$ \\
\hline 1 & 376 & 204 & 45 \\
2 & 1169 & 204 & 82 \\
3 & 759 & 193 & 75 \\
4 & 541 & 204 & 62 \\
5 & 579 & 198 & 65 \\
6 & 846 & 193 & 77 \\
\hline
\end{tabular}

\subsection{Site Class Liquefaction}

Site Class within the FEED has been identified as D. Site Class within the detailed design has been identified as E. However, at both cases the liquefaction potential analysis where the site class is utilized showed that liquefaction potential does not exist. 


\section{Discussions}

\subsection{Soil Strength Matters}

As shown above, soil strength on the FEED data is much higher compared to the strength on the detailed design soil data. However, comparison was made on "uncorrected" SPT N values that are not reliable as N value of a SPT test is affected by the hammer type and efficiency. It is not known whether both the FEED geotechnical report and detailed design geotechnical report have used manual or automatic SPT hammers and their efficiencies. A direct comparison of uncorrected $\mathrm{N}$ values is incorrect.

SPT hammers energy efficiencies can vary from $40 \%$ to $100 \%$. An example illustration is provided below where:

- A borehole from the FEED geotechnical report (BH D) is assumed to have an SPT hammer with energy efficiency of $50 \%$, and

- A borehole from detailed design geotechnical report (BH 4) is assumed to have an SPT hammer with energy efficiency of $90 \%$.

Both boreholes correspond to Area 4. A comparison of the soil strength related to boreholes $\mathrm{BH} \mathrm{D}$ (FEED) and $\mathrm{BH} 4$ (detailed) corresponding to Area 4 (by assuming SPT energy efficiencies of 50\% for FEED and 90\% for detailed) is provided in Figure 9.
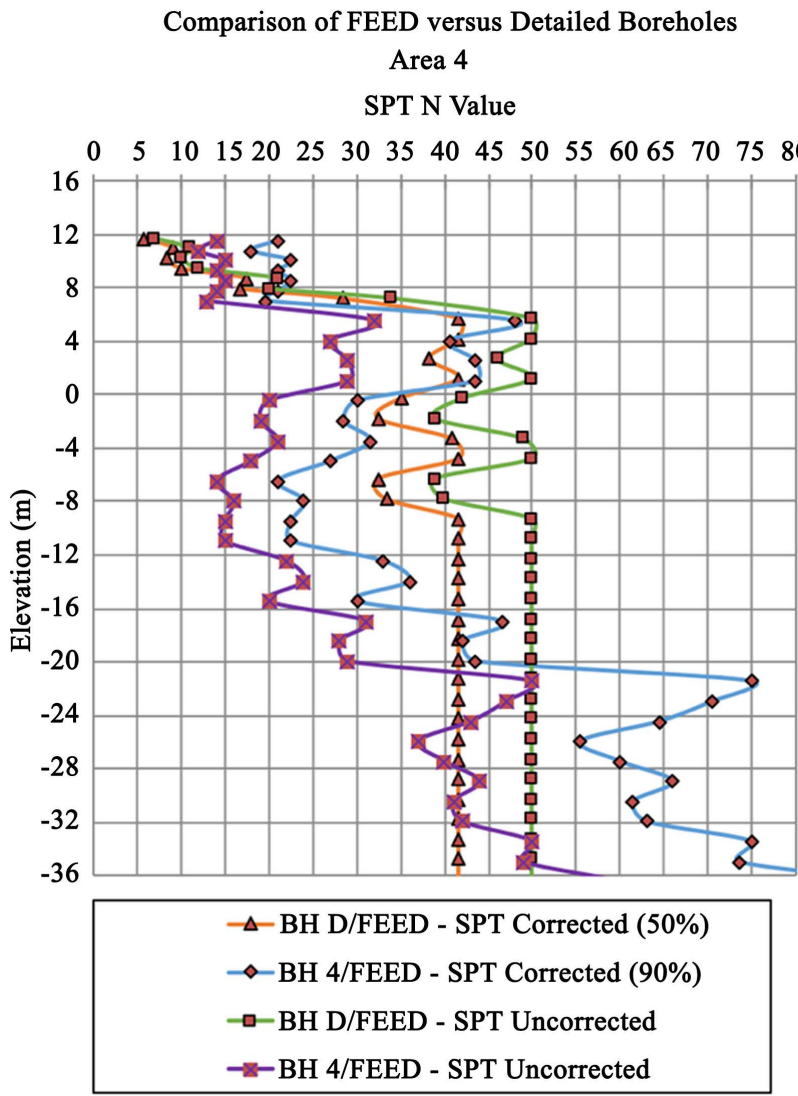

Figure 9. Strength comparison between the FEED and detailed campaigns by using uncorrected and corrected SPT values assuming hammer energy efficiencies. 
Figure 9 illustrates that the soil strength observed within the Detailed design geotechnical report is lower compared to the one reported within the FEED geotechnical data. However, the differences in soil strength have been reduced by assuming SPT Hammer efficiencies and at some places having similar values.

\subsection{Settlements Matters}

Based on above-mentioned assessments of settlements within both the FEED data and detailed design geotechnical report the following facts can be concluded:

- There was no specific recommendation in the FEED with regard to settlement tolerances. However, the settlement results presented in the FEED report show that settlements using the FEED borehole data are far beyond 50 $\mathrm{mm}$ (applicable for mat foundations) which would have required some degree of soil improvements.

- FEED document had estimated settlements exceeding those limits (50 $\mathrm{mm}$ ) which meant that foundations might have been failed without ground improvement works.

- FEED document has assessed structures with pressures of $200 \mathrm{kPa}$ and 100 $\mathrm{kPa}$ applicable for soil Groups 1 \& 2, respectively. In contrast, settlement analysis within the detailed design geotechnical report has considered actual imposed maximum loads of $220 \mathrm{kPa}$. Therefore, by applying the actual loads within the FEED soil data the settlements will be increased.

\subsection{Site Class Liquefaction Matters}

Site Class at FEED document assessed as D whereas during the detailed design investigation the Site Class was altered to E. However, at both cases it was identified that no ground improvement works due to liquefaction potential are required (such works are needed because of the estimated settlements being exceeded the tolerances).

\section{Conclusions}

Based on the analysis conducted, it is concluded that soil strength on the FEED data is much higher compared to the strength on the Detailed Design soil data.

Such soil changes have shifted the soil mitigation measures from light to severe. More specifically, the FEED geotechnical data implied ground improvement measures by means of shallow schemes and techniques (e.g. dynamic and rapid impact compaction, excavation and soil replacement) since granular sandy loose materials exist at the top $5 \mathrm{~m}$. On the other hand, the detailed design geotechnical data show soft cohesive formations having thicknesses of up to $20 \mathrm{~m}$ resulting on soil mitigations by means of vibro stone columns and dynamic compaction/replacement that are much more costly and time consuming compared to the shallow soil mitigations.

These soil differences found within the two geotechnical campaigns at approximate similar locations can be attributed to the following factors: 
- Uncorrected SPT N values have been utilized for estimating the settlements and bearing capacities. Such figures are not reliable as N value of a SPT test is affected by the hammer type and efficiency. It is not known whether both the FEED geotechnical report and detailed design geotechnical report have used manual or automatic SPT hammers and their efficiencies.

- The workmanship of the two geotechnical investigations is in question whether they have been correctly executed. Subject paper utilizes the factual data as default values since no supervision of the campaigns was taken place.

- The soil formations within small distances were exhibited considerable variations on soil strength and composition. This can be possible since areas under consideration are close to the shore and soft pockets of subsurface deposits may exist in between more or less stronger formations.

\section{Conflicts of Interest}

The authors declare no conflicts of interest regarding the publication of this paper.

\section{References}

[1] Arvind Patel (2008) Best Practices in Front-End Design, Bently Sustainable Infrastructure.

[2] Abdulrahman, Y., Gibson, G. and Ramsey, D. (2018) Front End Engineering Design (FEED) for Large Industrial Projects: FEED Maturity and its Impact on Project Cost and Schedule Performance. Construction Research Congress 2018, New Orleans, LA. USA. https://doi.org/10.1061/9780784481295.001

[3] Investing in Infrastructure, 2016, Position Paper on Contracting Delivery Models, International Best Practice in Project and Construction Agreements, Australia. http://www.pwc.com.au/

[4] Whiteside, J.D., II, P.E. and Humes, T. (2010) Front-End Engineering and Design: Influence over a Project's Outcome. AACE International Transactions.

[5] ASTM D1586-99, Standard Test Method for Penetration Test and Split-Barrel Sampling of Soils, ASTM International, West Conshohocken, PA, 1999.

https://www.astm.org/

[6] Schmertmann, J.H., Hartman, J.P. and Brown, P.R. (1978) Improved Strain Influence Factor Diagrams. Proceedings of the American Society of Civil Engineers, 104, 1131-1135.

[7] ASCE 7-05, Minimum Design Loads for Buildings and other Structures, 2006. 